\title{
Review
}

\section{The origin and function of self-incompatibility in flowering plants}

\author{
R.G. Olmstead \\ Department of Biology, University of Michigan, Ann Arbor, MI 48109, USA
}

Summary. The evolutionary significance of self-incompatibility (SI) traditionally has been linked to reduced inbreeding through enforced outcrossing. This view is founded on the premise that outcrossing reduces inbreeding. It is important, when considering the evolutionary significance of any genetic system, to try to distinguish those factors related to the evolution of, from those related to the maintenance of, the system in question. Three factors are considered important for the maintenance of SI: (1) phylogenetic constraint in species descended from SI ancestors, (2) reduced inbreeding in populations, and (3) fitness benefits to individuals resulting from the avoidance of selfing. I suggest that the first two factors should be rejected when considering the origin of SI (whether one or more origins are hypothesized) and that the increase in individual fitness resulting from the avoidance of selffertilization among individuals that are heterozygous for deleterious alleles may be sufficient to account for the origin of SI. Self-fertilization in plants (except in species that predominantly selffertilize) generally results in a reduction in fitness of some individuals due to the increased expression of deleterious or lethal recessive alleles, regardless of the degree of inbreeding in the population or the frequency of the allele in question. Inbreeding is a consequence of population structure in many outcrossing plant species. Complex (multi-locus and multi-allelic) systems of SI exist that reduce inbreeding. However, it is argued that these are derived either from simpler systems of SI that may have very little or no effect on inbreeding, in which case any effect on level of inbreeding is secondary, or are not true self-incompatibility systems and are part of a regulatory system that serves to balance the level of inbreeding and outbreeding. Multi-locus and multi-allelic systems of SI and heteromorphic systems of SI are discussed in terms of derived versus ancestral characteristics. A reassessment of the role of breeding systems in the development of a population structure promoting inbreeding is suggested, which may have been of crucial importance in the success and diversification of angiosperms.

Key words: Self-incompatibility - Breeding systems - Population structure.

\section{Introduction}

Breeding systems evolve. Can the function of a particular breeding system explain the origin of that system, or only explain the maintenance of that breeding system in the selective environment in which it exists today? It is logical to try to separate the reasons for the origin of various breeding systems from the reasons for their maintenance. This is often a difficult task, given the multiple effects on fitness that a change in reproductive behavior may entail. Consider, for example, the multitude of arguments that have been offered for the evolution of dioecism in plants (Darwin 1876; Baker 1959; Lloyd 1979; Bawa 1980; Beach and Bawa 1980; Beach 1981; Thompson and Barrett 1981; Givnish 1982; Willson 1983).

The expression of SI takes many forms. De Nettancourt (1977) attempted a classification of SI systems based on variation in the time of gene action, the association with floral polymorphism, the site of expression, and the number of loci and alleles involved. He discussed SI systems that differ at all of these levels. Lewis (1979) cites at least 11 different genetically controlled SI systems. Systems that involve dicliny, dichogamy, and structural mechanisms of flowers also may function more or less effectively as outcrossing systems (from 
complete avoidance of selfing in dioecism to systems with a potential for geitonogamous self-pollination), in addition to the genetic systems that involve self-recognition. The avoidance of selfing is the effect common to all SI systems (here including all breeding systems that restrict self-fertilization) and the only genetic effect of some breeding systems (e.g., dioecism, temporal dioecism, and distyly). Additionally, many SI systems result in a certain amount of cross-incompatibility, sometimes at random in the population with respect to the genetic relatedness of the individuals (distyly, single locus sporophytic SI, dioecism), or, in the case of multi-locus and multi-allelic systems (especially gametophytic self-incompatibility), an increase in cross-incompatibility among genetically related individuals.

The traditional explanation for the evolution of self-incompatibility (SI) is that it arose as a mechanism to promote outcrossing and minimize inbreeding in flowering plant populations (Darwin 1876; de Nettancourt 1977). As others have pointed out, this need not rely on a group selection argument (Charlesworth and Charlesworth 1979a; Lloyd 1979). I suggest that the maintenance of SI is largely independent of the level of inbreeding in a population and that the origin of SI is probably independent of any effect it may have on the level of inbreeding in populations.

The level of inbreeding in a population is much more likely to be controlled by population size effects than by whether the plant species has a selfincompatible or self-compatible breeding system (Olmstead 1986). It is not necessary that self-incompatible species be highly outbred nor that selfcompatible species be highly inbred (although certain self-compatible species may be highly self-fertilizing and extremely inbred). Yet, it is such assumptions, implicit in the traditional explanation, that have led some authors to equate self-incompatibility with outbreeding and self-compatibility with inbreeding in natural populations (Ruiz et al. 1978; Opler et al. 1980; Sobrevila and Arroyo 1982; McLeod et al. 1983; Wiens 1984).

\section{Maintenance of self-incompatibility}

Inbreeding depression has been cited most often as the phenomenon responsible for the maintenance of SI (de Nettancourt 1977; Maynard Smith 1978; Charlesworth and Charlesworth $1979 \mathrm{a}$, b; Barrett 1988). At the population level, inbreeding depression is a reduction in the mean of individual fitnesses over the entire population. This can be manifested in more than one way. The gradual decrease in heterozygosity as a population becomes increasingly inbred may cause a general reduction in fitness throughout the population. Another manifestation of inbreeding depression, however, is the dramatic reduction in fitness of some individuals in the population, i.e., those carrying recessive lethal or deleterious alleles. This may come about through the greater probability of the expression of recessive lethal or deleterious alleles when selfing than when outcrossing. A model addressing the effect that avoiding selfing has on these two manifestations of inbreeding depression has been presented (Olmstead 1986) and is summarized in the following section. Reduced levels of inbreeding may result from incompatible crosses among related individuals in plants with multi-locus and multi-allelic systems of SI. It is argued here that multi-locus and multi-allelic systems of SI are derived from simpler systems, and the effect that such systems may have in reducing levels of inbreeding may be important only in their maintenance once established.

There is another important, "silent" reason for maintenance of SI systems in many species. Selfincompatibility systems are, in most cases, the product of strongly conserved genetic systems and exist in many species as a constraint of their evolutionary history.

\section{The consequences of avoiding selfing in plant populations}

Avoidance of selfing is an outcome common to all SI systems. The effect of eliminating selfing from a population may be reviewed in two contexts: as it relates to the reduction in the level of inbreeding in the population as a whole (expressed as the inbreeding coefficient, $F$; Wright 1922), and also as it relates to the fitness of individual members of the population. The first of these may be relatively trivial, but the latter appears to be significant.

The level of inbreeding in a population, represented by the inbreeding coefficient, $F$ (Wright 1922), will increase over time at a rate dependent upon the effective population size, $N_{\mathrm{e}}$, such that: $\Delta F=1 /\left(2\left(N_{\mathrm{e}}\right)\right.$ per generation (Falconer 1960). An equilibrium level of inbreeding that is somewhat lower than the level suggested by population size alone may be maintained by the effects of mutation, gene flow from adjacent populations, and selection for genetic polymorphism. Small populations will, therefore, become inbred more rapidly and reach a higher equilibrium level of inbreeding (Fig. 1). 


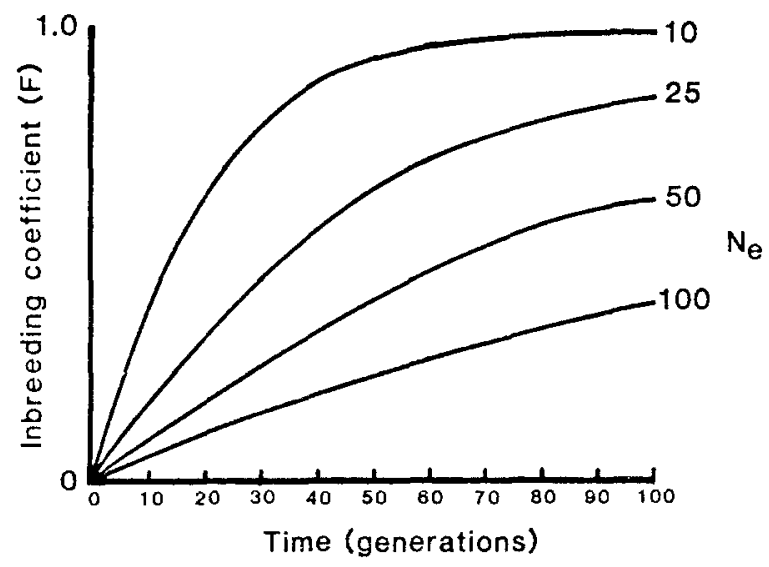

Fig. 1. The relationship between effective population size, $N_{e}$, and the level of inbreeding, represented by the inbreeding coefficient, $F$, over time, in generations (after Parkin 1979)

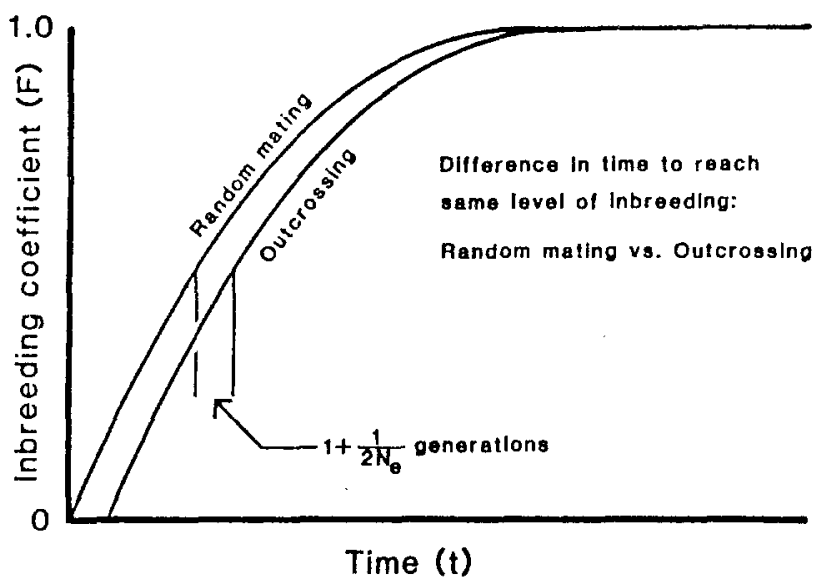

Fig. 2. Difference in time, $1+1 /\left(2 \mathrm{~N}_{\mathrm{e}}\right)$ generations, required to reach the same level of inbreeding in a random mating population (selfing allowed) and in an obligately outcrossing, but otherwise random mating, population

Avoidance of selfing in a random mating population would have an effect on the level of inbreeding that closely approximates an increase in effective population size of one-half an individual (Crow and Kimura 1970):

$N_{\mathrm{e}}$ (outcrossing) $=N_{\mathrm{e}}$ (random) $+1 / 2$.

The difference in time required by a population that does not self (i.e., outcrossing) to reach the same level of inbreeding as a population in which selfing is allowed (with random mating) results from the greater effective population size of the second population (one-half individual) and equals approximately $1+1 /\left(2 N_{\mathrm{e}}\right)$ generations (Fig. 2$)$. Both populations will reach similar equilibrium levels of inbreeding with the outcrossing popula-

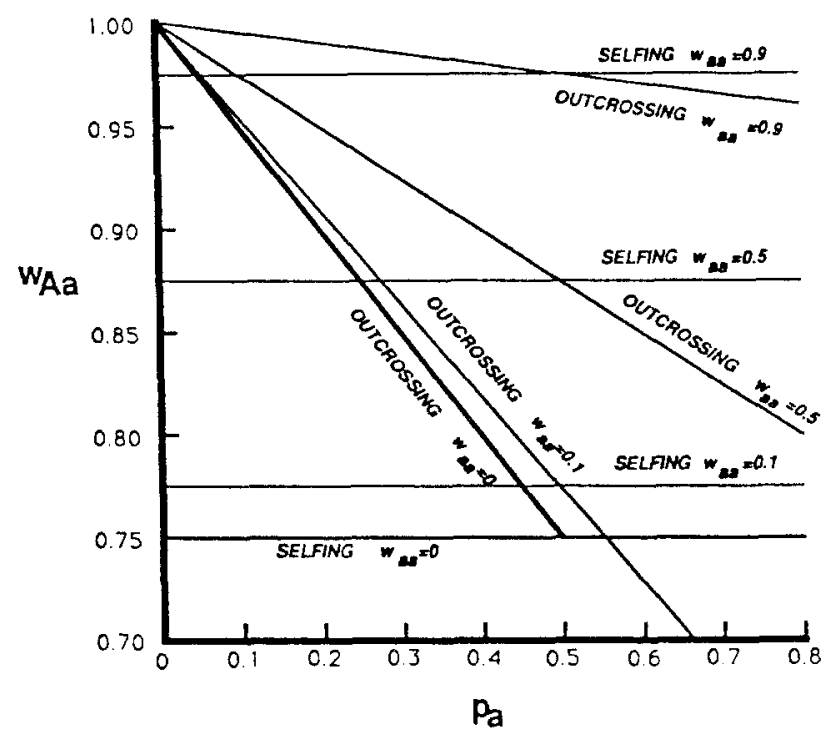

Fig. 3. Mean fitness of individuals heterozygous, $w_{A a}$, for lethal recessive alleles (homozygote fitness, $w_{a a}=0$ ) and deleterious recessive alleles ( $w_{a a}$, equal to $0.1,0.5$, and 0.9 ) when selfing and when outcrossing. Frequency of deleterious or lethal allele equals $p_{a}$

tion perhaps equilibrating at a slightly lower, but not substantially different, level.

In contrast to the effect on the level of inbreeding, the difference in fitness between outcrossing and selfing individuals can be dramatic. A primary cause of inbreeding depression is the increase in homozygosity in the population (Wright 1922), which causes a reduction in fitness in some individuals resulting from the increased occurrence of deleterious or lethal recessive alleles in the homozygous state. Most deleterious alleles exist as recessives (Muller 1950) and occur in a population at low frequencies. Therefore, they will most likely be found in the heterozygous condition. By selfing, a greater proportion of those alleles will occur in a homozygous state than would occur through cross-pollination.

In the case of a deleterious or lethal recessive allele, a, the relative fitness (in terms of the expected survival of its offspring compared to AA) of an individual heterozygous, $\mathrm{Aa}$, at the locus in question will differ depending on whether it is selfor cross-fertilized. The relative fitness will be fixed (as low as 0.75 for a lethal recessive) when selffertilizing, regardless of the frequency of the allele in the population (Fig. 3). When outcrossing, the mean fitness of individuals heterozygous at the locus in question will depend on the frequency of the recessive allele in the population. The effective reduction in relative fitness of the heterozygote for a deleterious allele is less than that for a lethal 
allele, but the pattern is similar. The difference in mean fitness between heterozygous individuals that are outcrossed and selfed is most pronounced at the low frequency with which a lethal recessive would be expected to occur in a population, as in the case of a recently arisen mutation. Selection on a nascent, self-incompatible breeding system could act more rapidly in the situation in which there is heterozygote advantage (overdominance) for new mutations, by increasing the frequency of heterozygotes and creating more opportunity for selection to act. This difference in fitness among individuals may be enough to account for the evolution and maintenance of any breeding system that avoids selfing, regardless of the degree of inbreeding in the population.

Obviously, panmictic populations, with and without selfing, are not commonly observed in nature. However, the theoretical analysis of the effect on the level of inbreeding and effective population size of the avoidance of selfing outlined above provides a point of departure from which to consider natural populations. Due to the vagaries of pollination and seed dispersal, breeding is often far from random, and in most self-compatible species the incidence of selfing exceeds that expected under a random distribution of gametes. Two effects of this departure from random mating are pertinent to the discussion of inbreeding and the avoidance of selfing. First, if there is an increased incidence of selfing in a natural, self-compatible population, the avoidance of selfing would reduce the level of inbreeding $(F)$ in the population as a whole to a greater extent than the avoidance of selfing would reduce $F$ in a truly panmictic population. Second, non-random mating has the effect of reducing effective population size $\left(N_{\mathrm{e}}\right)$. This reduction in $N_{\mathrm{e}}$ accelerates the rate at which $F$ increases, thereby countering, to a degree, the reduction in F resulting from the avoidance of selfing. At the same time, an increased selfing rate exposes more of the deleterious or lethal alleles, sheltered in the heterozygous state, to selection, thereby increasing the rate at which selection can act on any associated genetic system that avoids selfing.

If, as is argued here, SI is the result of selection against selfing in non-random mating populations, while at the same time not substantially reducing the level of inbreeding in those populations, then one might expect to find self-incompatible species that exhibit greater levels of inbreeding than do related self-compatible species. Very few studies are available in which a comparison of relative levels of inbreeding can be made between closely related taxa that are self-compatible and self-incom- patible. In one such study, McCleod et al. (1983) examined seven undomesticated species of Capsicum. Six species were self-compatible and one was self-incompatible. One of the two species exhibiting the greatest degree of inbreeding (less than $1 \%$ mean heterozygosity) was the single self-incompatible species.

\section{Evolution of self-incompatibility}

Little is known about the evolution of SI. Much of what has been suggested is inference drawn from analyses of the phylogenetic distribution of SI in flowering plants (East 1940; Whitehouse 1950), the function of SI in plant breeding studies (East and Mangelsdorf 1925; Whitehouse 1950; Bateman 1952; Lundquist 1975; Larsen 1977), or the dynamics of complex systems of SI in natural populations (Emerson 1938; Campbell and Lawrence 1981). The association of breeding systems with various attributes of plant population structure has been considered theoretically (Charlesworth and Charlesworth 1979a; Shields 1982; Lande and Schemske 1985; Holsinger 1986; Uyenoyama 1988 b) and by comparison of outcrossing rates in plant populations (Schemske and Lande 1985).

The population structure considered most susceptible to the advantages of an SI system is one in which the population size is relatively small, mating is more or less at random with some selffertilization, and reproductive capacity is moderate (Charlesworth and Charlesworth 1979 a, b; Shields 1982; Uyenoyama 1988 b). Many population structures are not expected to favor the evolution of SI. Species composed of large populations with widespread pollen and/or seed dispersal and high fecundity will maintain an adequate amount of gene flow and reproductive capacity to tolerate a low level of selfing (Lande and Schemske 1985; Schemske and Lande 1985). Species with high levels of selfing will most likely maintain very low levels of deleterious or lethal alleles (Stebbins 1957; Mather 1973; Lande and Schemske 1985; Schemske and Lande 1985) or may depend on selffertilization in the absence of adequate population density or pollinator activity (Stebbins 1957). Species with small effective population sizes that exhibit very low levels of selfing as a result of effective structural or temporal outcrossing mechanisms will not be affected strongly enough by the fitness differential between the rare selfing events and the predominant outcrossing to evolve an SI system (Kress 1983).

An attempt to ascertain the possible effect that 
the origin of an SI system may have on the genetic structure of a population requires that derived complex systems of SI be identified and removed from consideration. Breeding systems may be considered as phylogenetic characters with functional character "states". It is then axiomatic that the derived states/functions are different from the ancestral states/functions and that any inference to be drawn regarding the evolution of the ancestral state (in this case the original SI condition) must consider only the ancestral function for that breeding system. Attributes of breeding systems that are derived should not be confused with the attributes of the ancestral breeding system when trying to infer an agent of selection for the original system. A genetic system that evolved for one purpose may be co-opted for another purpose or for additional purposes (Gould and Vrba 1982). The following suggestions remain speculative at best, but insight can be gained by narrowing the field of potential breeding systems and their effects.

\section{Genetic SI systems}

Complex multi-locus and single-locus, multi-allelic systems of SI exist in which cross-incompatibilities are more common among sibs and closely related individuals than at random within the population. This implies that selection is acting against inbreeding per se as well as against selfing. However, the origin of complex SI systems should be considered before inferring a causal relationship for the evolution of such systems. Most SI systems existing in nature today are probably derived from more primitive SI systems and may have effects not attributable to the original SI system from which they are derived. For example, sporophytic selfincompatibility (SSI) has been considered to be derived from gametophytic self-incompatibility (GSI) on both theoretical (Whitehouse 1950; Grant 1975; de Nettancourt 1977; Beach and Kress 1980) and phylogenetic considerations (Brewbaker 1967). If SSI is derived from GSI, it would be inappropriate to base an explanation for the evolution of SI on the functional attributes of an SSI system (but see recent evidence from S-gene sequencing studies, Nasrallah et al. 1985; Anderson et al. 1986).

Gene duplication may be the most likely explanation for multi-locus SI systems in general (Larsen 1985; personal communication). Gene duplication results from either polyploidy or from chromosomal mutations in diploids. In hexaploid Chrysanthemum, a SSI system composed of three loci acting in a complementary fashion has been pro- posed (Jagorski et al. 1983), suggesting duplication of the $S$-gene by polyploidy. However, in some cases, polyploidy in plants with GSI systems will result in the loss of self-incompatibility (de Nettancourt 1977).

In diploid species, duplicate loci will assort independently when the duplication is the result of chromosomal rearrangements (translocations between nonhomologous chromosomes, for example) or will be tightly linked when the result of unequal crossing-over (Gottlieb 1982). While independent origins of multiple incompatibility loci in the same species cannot be ruled out in systems with two or more loci, the selective advantage gained by the addition of a second locus to an established SI system is probably too small for the potential reduction in fertility required by the establishment of an additional incompatibility locus (Charlesworth and Charlesworth 1979a). The two-locus system of gametophytic self-incompatibility (GSI) in grasses has been proposed to be derived from a single-locus system by gene duplication (Lundqvist 1962). Likewise, the independent nature of the multi-locus systems of GSI known in Beta (Larsen 1977) and Ranunculus (Lundqvist 1975) and their complementary mode of action fit a model of duplicative origin (K. Larsen, personal communication). An alternative explanation, based on the presumed antiquity of the two families (Chenopodiaceae, Ranunculaceae), suggests that the multi-locus systems found in Beta (at least four loci) and Ranunculus (at least three loci) are primitive and ancestral to the more common single-locus systems (Lundqvist 1975; Barrett 1988). The multiple loci are presumed to be silenced by fixation for a single allele. The age of these two ancient lineages makes it equally likely that the existence of multi-locus systems in these plants are derived from a single locus in that there has been plenty of time for the accumulation of gene duplications. The gene duplication model has the advantage over the ancestral multi-locus model of Lundqvist (1975) in that no ad hoc explanation is needed for the origin of multi-locus systems in primitive angiosperms.

Single-locus, multi-allelic systems are common in GSI. A triallelic system is the simplest and perhaps the primitive form of GSI (Whitehouse 1950; but see Bateman 1952). The origin of a primitive GSI system has been modeled beginning with a single allele conferring partial or complete incompatibility in a locus at which other alleles do not affect compatibility (Charlesworth and Charlesworth 1979 b; Uyenoyama 1988 b). In a triallelic system three, compatibility genotypes exist: $S_{1} S_{2}$, $S_{1} S_{3}$, and $S_{2} S_{3}$. When the incompatibility response 
is complete, the probability of cross-compatibility between any two genotypes is 0.5 , and the probability of cross-compatibility between individuals sharing the same compatibility genotype is 0 (the same probability as for self-compatibility). As additional alleles enter the population, more compatibility types exist, and a proportion of the random crosses will be fully compatible. This proportion increases as the number of alleles increases.

In the simple three-allele case, selection against sib mating as well as selfing will occur, but the effect nearly disappears one generation removed (i.e., the probability of first cousin cross-compatibility is nearly equal to random cross-compatibility). In the multi-allelic case, more cross-incompatibility will be exhibited among closely related plants than at random among the population. A strong argument exists, however, that the additional Salleles are maintained in the population due to the increased fitness they confer on the individuals bearing them when they are rare (Wright 1939; Ewens 1964), rather than for the effect they have on the level of inbreeding. Wright (1939), considering evidence from Oenothera organensis (Emerson 1938), showed that once a GSI system has been established, any new allele that arises will be favored. The number of alleles in a population will increase to an equilibrium level dependent on population size (Wright 1939; Ewens 1964; Nagylaki 1976). Wright's explanation suggests that multiallelic systems most likely are derived from simpler systems. Therefore, the reduction in inbreeding is more likely a secondary effect rather than a primary cause for the origin of the SI system.

In the ideal case of GSI discussed above, crosses between different compatibility types will be fully compatible; however, intermediate levels of compatibility exist in nature, and these have been considered to be the result of quantitative interactions with other loci (Ascher 1984) or even as evidence that GSI does not exist as conventionally conceived (Mulcahy and Mulcahy 1983; but see Lawrence et al. 1985). In the heterosis model of Mulcahy and Mulcahy (1983), GSI may not be a true self-recognition SI system in the conventional sense, but rather the result of prezygotic selection against deleterious recessive alleles. If this is the case, then GSI is an effect of the increased homozygosity resulting from inbreeding rather than a mechanism to prevent selfing, and it is not surprising that it is a widespread phenomenon in inbred angiosperm populations. Uyenoyama (1988 a) has proposed a mechanism for the origin of an incompatibility locus through associative overdominance resulting from the identity disequi- librium that might arise in an inbred population between an incompatibility locus and a locus under strong selection.

If the heterosis model is correct, or if GSI originated as a multi-locus system involving partial incompatibility, then selection against inbreeding is the expected outcome of the accumulation of lethal and deleterious recessive alleles, and such cases of GSI should be removed from consideration as SI systems and belong to the category of feedback mechanisms that control the balance between excessive outbreeding and too narrow inbreeding (Partridge 1983; Shields 1983; Uyenoyama 1988a).

\section{Heterostyly}

The close phylogenetic association of tristyly with distyly (usually in the same genus, Ganders 1979) and much of what is known about their genetic control suggests that the two-locus heteromorphic SI system associated with tristyly may be of duplicative origin (Richards 1986). Tristyly has probably evolved independently in each of the three families in which it is known (Barrett 1985). Yet the genetic control of the floral heteromorphism and the physiological SI usually associated with it are quite similar in all three families. Two loci are commonly reported to control both the floral heteromorphism and the SI specificity in tristylous flowers, while one locus controls each in typical distylous plants (Ganders 1979). If gene duplication of the distyly "supergene" (tightly linked loci for the floral heteromorphism and SI response) was responsible for the origin of tristyly, then a functionally different, though genetically redundant, system would arise.

In families in which both distyly and tristyly are found in related species, distyly has been shown to be derived from tristyly through the breakdown of the genetic system controlling the floral heteromorphism. Breakdown of the genetic control of tristyly may be predicted in such a redundant system because selection may not act so strongly on each locus, especially when the breakdown often results in a functional dimorphic SI system, as is the case in the families Oxalidaceae and Lythraceae (Mulcahy 1964; Weller 1976; Lewis and Rao 1971). In the Pontederiaceae, the modifying effect of other genes may have altered the action of the original or duplicate supergene so that its breakdown will not yield a functional dimorphic SI system.

In some cases where the breakdown of tristyly results in distyly, the resulting distyly is atypical. Often the mid-length style is missing, but all three 
stamen lengths remain (Mulcahy 1964; Lewis and Rao 1971). If the supergene is composed of more than one locus controlling floral heteromorphism (e.g., separate loci for style length, stamen length, and pollen grain size) (Muenchow 1981), then a duplication in that region of a chromosome would be expected to duplicate all of the tightly linked loci in the supergene, but subsequent mutations may silence one locus independently of the others. Deactivation of a duplicate style length locus, for example, may result in loss of the mid-length style from a population, leaving the mid-length stamen locus subject to selection and the action of modifiers to become functionally long or short depending on the style morph with which it is associated. This scenario offers an explanation for the breakdown of tristyly to distyly as observed in Oxalis section Corniculatae (Mulcahy 1964) and in Pemphis (Lewis and Rao 1971). The case of typical distyly resulting from the breakdown of tristyly, reported by Weller (1976) in Oxalis section Jonoxalis, may be the result of a deactivating mutation affecting both tightly linked loci for style and stamen length.

The breakdown of tristyly has been well studied, both theoretically (Charlesworth 1979) and empirically, in all three families in which it is known to exist (Lythraceae, Lewis and Rao 1971; Oxalidaceae, Mulcahy 1964; Weller 1976; Pontederiaceae, Barrett 1979), but little is known regarding the evolution of tristyly (Charlesworth 1979; Barrett 1985). The suggestion that gene duplication is responsible may be little more than speculation at this point, but may provide a hypothesis that can be tested by the application of molecular techniques to assess the structural similarity of the genes controlling heteromorphic SI in tristylous plants as has been done recently for the S-genes in Brassica oleracea (Nasrallah et al. 1985) and $\mathrm{Ni}$ cotiana alata (Anderson et al. 1986).

The complex SI systems considered (above) to be derived (i.e., multi-locus and multi-allelic GSI, multi-allelic SSI, tristyly, and distyly derived from tristyly) include those SI systems that are most likely to exhibit selection against inbreeding via incompatible matings among genetically related individuals, as well as by self-incompatible matings. If one considers the remaining potentially "primitive" systems of SI, including the simple case of GSI, diallelic SSI, distyly, dioecism, and even temporal and mechanical systems that avoid selfing (e.g., temporal dioecism, Cruden 1988), many of which may have numerous independent origins, the common thread remains prevention of selfing rather than prevention of inbreeding, per se.

\section{Self-incompatibility and angiosperm phylogeny}

The phylogenetic origin of SI has remained for many years a topic of debate. Whether SI has arisen once or many times in the angiosperms, it must have been derived at some time from primitively self-compatible stock. Self-incompatibility is $a b-$ sent in extant gymnosperms and is rarely found in "primitive" woody angiosperms (possible exceptions include one species each in the Illiciaceae, Magnoliaceae, and Winteraceae; Charlesworth 1985). Arguments exist for and against the monophyletic origin of SI. The occurrence of similar SI systems, notably GSI, in distantly related families provides the basis for the theory that GSI is of monophyletic origin and arose very early in the evolution of the angiosperms (Whitehouse 1950; Brewbaker 1967; Crowe 1964; de Nettancourt 1977; Heslop-Harrison 1983). In this argument, the inferred advantage of SI in reducing inbreeding is suggested to have contributed to the rise of angiosperms (Whitehouse 1950; de Nettancourt 1977).

Alternatively, the homogeneity of SI systems within families compared with the variety among families (Charlesworth 1985), the presence of numerous unrelated systems that avoid selfing (mechanical, temporal, and physiological), the lack of sequence homology between presumed $S$-genes of Brassica and Nicotiana (Nasrallah et al. 1985; Anderson et al. 1986), and the absence of GSI in gymnosperms and its rarity in primitive angiosperm families forms the basis for the argument that SI has arisen independently many times in the course of angiosperm evolution (East 1940; Bateman 1952; Grant 1975; Ganders 1979; Charlesworth and Charlesworth 1979b). Both of these alternative views are consistent with the traditional assumption that minimizing inbreeding is the primary role of SI, whereas the argument presented here only supports a multiple origin of self-incompatibility.

The theory that insect pollination was a significant factor in the early success of angiosperms (Stebbins 1974; Regal 1977) is pertinent to this debate in light of the potential benefits of inbreeding. Insect pollination allows greater mate discrimination and pollination success in small populations or populations of scattered individuals (Regal 1977; Stebbins 1974; Doyle and Hickey 1976; Crepet 1983). Such population structure promotes genetic differentiation (Levin and Wilson 1978) and may allow greater opportunity for diversification and occupation of new adaptive zones (Wright 1940; Mayr 1963; Stebbins 1974) than previously 
possible in less discriminating wind-pollinated gymnosperms.

If SI evolved, as previously assumed, to increase outbreeding, then it should not be viewed as playing a progressive role in angiosperm evolution. Outbreeding delays population differentiation and is therefore not expected to be a factor promoting rapid diversification of angiosperms. If, as is argued here, SI is a response to the accumulation of deleterious recessive alleles, then SI may be a side effect of the otherwise beneficial nonrandom mating and inbreeding in angiosperm populations. Wind-pollinated and other widely outbreeding plant populations are constrained to differentiate more slowly by the buffering effect of a greater amount of gene flow and lesser amount of subdivision expected to occur within populations (Levin 1981; Loveless and Hamrick 1984). Plants with more discriminating pollination modes will evolve more readily via population differentiation and cladogenesis (Crepet 1984). Thus, the increased levels of inbreeding resulting from the smaller effective population sizes made possible by insect pollination may be the most important aspect in the successful diversification of angiosperms. Angiosperm success may be a consequence of a greater propensity on the part of angiosperm populations to inbreed and, therefore, to differentiate, rather than a consequence of any adaptive functional morphology that allowed them to outcompete their gymnospermous predecessors.

\section{Conclusions}

Three factors contributing to the maintenance of self-incompatibility can be identified. First is the constraint of phylogenetic history in species derived from ancestors having SI systems. Second is a reduction in the level of inbreeding resulting from either the avoidance of selfing or as a consequence of cross-incompatibilities among genetically related individuals in multi-locus or multi-allelic SI systems. Third is the advantage to individual fitness of avoiding selfing in any population.

A consideration of the three factors listed above leads to the rejection of the first two as explanations for the origin of SI. The absence of SI in the extant sister groups of the angiosperms probably means that phylogenetic constraint played no role in the initial appearance of SI in angiosperms. Likewise, reducing inbreeding is not a likely factor in the origin of SI for two reasons: (1) multi-locus and multi-allelic systems are probably derived secondarily from simpler more primi- tive systems that do not substantially reduce inbreeding and (2) the reduction in inbreeding that the avoidance of selfing incurs is inconsequential in most plant populations. Selection controlling levels of inbreeding is no doubt important in flowering plant populations, but is most likely aimed at maternal effects on seed maturation, variable fitness of progeny in a mixed mating system, and characters directly associated with gene flow such as pollen and seed dispersal. Thus, the advoidance of selfing, specifically the fitness advantage accrued through the avoidance of selfing by individuals heterozygous for deleterious or lethal alleles, emerges as the most likely agent of selection in the origin of self-incompatibility.

Acknowledgements. I thank the following people for beneficial discussions and critical comments on early drafts of the manuscript: W. DiMichele, J. Davis, S. Barrett, R. Shaw, J. Felsenstein, D. Mulcahy, W. Shields, R. Burnham, M. Denton, D. Waller, K. Holsinger, A. Kruckeberg, and J. Beach, and an anonymous reviewer.

\section{References}

Anderson M, Cornish E, Mau S, Williams E, Hoggart R, Atkinson A, Bonig I, Grego B, Simpson R, Roche R, Haley J, Penschow J, Niall H, Tregear G, Coghlan J, Crawford R, Clarke A (1986) Cloning of cDNA for a stylar glycoprotein associated with expression of self-incompatibility in $\mathrm{Ni}$ cotiana alata. Nature $321: 38-44$

Ascher PD (1984) Discriminating styles and pollen-mediated pseudo-self compatibility. Am J Bot 71 (5, part 2):98

Baker H (1959) Reproductive methods as factors in speciation in flowering plants. Cold Spring Harbor Symp Quant Biol $24: 177-191$

Barrett S (1979) The evolutionary breakdown of tristyly in Eichornia crassipes (Mart.) Solms (water hyacinth). Evolution 33:499-510

Barrett S (1985) Ecological genetics of breakdown in tristyly. In: Haeck J, Woldendorp JW (eds) Structure and functioning of plant populations, vol 2. North Holland, Amsterdam New York, pp 267-275

Barrett S (1988) The evolution, maintenance, and loss of selfincompatibility systems. In: Lovett-Doust $\mathbf{J}$, Lovett-Doust L (eds) Plant reproductive ecology. Oxford University Press, New York, pp 98-124

Bateman AJ (1952) Self-incompatibility systems in angiosperms. I. Theory. Heredity $6: 285-310$

Bawa K (1980) Evolution of dioecy in flowering plants. Annu Rev Ecol Syst 11:15-39

Beach J (1981) Pollinator foraging and the evolution of dioecy. Am Nat 118:572-577

Beach JH, Bawa K (1980) Role of pollination in the evolution of dioecy from distyly. Evolution 34:1138-1142

Beach JH, Kress WJ (1980) Sporophyte versus gametophyte. A note on the origin of self-incompatibility in flowering plants. Syst Bot $5: 1-5$

Brewbaker JL (1967) The distribution and phylogenetic significance of binucleate and trinucleate pollen grains in the angiosperms. Am J Bot 54:1069-1083 
Campbell JM, Lawrence MJ (1981) The population genetics of the self-incompatibility polymorphism in Papaver rhoeas. II. The number and frequency of S-alleles in a natural population (R106). Heredity 46:81-90

Charlesworth D (1979) The evolution and breakdown of tristyly. Evolution 33:486-498

Charlesworth D (1985) Distribution of dioecy and self-incompatibility in angiosperms. In: Greenwood J, Slatkin M (eds) Evolution - essays in honour of John Maynard Smith. Cambridge University Press, Cambridge, pp 237-268

Charlesworth D, Charlesworth B (1979a) The evolutionary genetics of sexual systems in flowering plants. Proc R Soc London Ser B 205:513-530

Charlesworth D, Charlesworth B (1979b) The evolution and breakdown of S-allele systems. Heredity 43:41-55

Crepet WL (1983) The role of insect pollination in the evolution of the angiosperms. In: Real L (ed) Pollination biology. Academic Press, Orlando, Fla, pp 29-50

Crepet WL (1984) Advanced (constant) insect pollination mechanisms: patterns of evolution and implications vis-avis angiosperm diversity. Ann Mo Bot Gard 71:607-630

Crow JF, Kimura M (1970) An introduction to population genetics theory. Harper \& Row, New York

Crowe LK (1964) The evolution of outbreeding in plants. I. The angiosperms. Heredity 19:435-457

Cruden RW (1988) Temporal dioecism : systematic breadth, associated traits, and temporal patterns. Bot Gaz (Chicago) $149: 1-15$

Darwin C (1876) The effects of cross- and self-fertilization in the vegetable kingdom. Murray, London

Doyle JA, Hickey LJ (1976) Pollen and leaves from the MidCretaceous Potomac Group and their bearing on early angiosperm evolution. In: Beck CB (ed) Origin and early evolution of angiosperms. Columbia University Press, New York, pp 139-206

East EM (1940) The distribution of self-sterility in the flowering plants. Proc Am Philos Soc 82:449-518

East EM, Mangelsdorf AJ (1925) A new interpretation of the hereditary behavior of self-sterile plants. Proc Natl Acad Sci USA 11:166-177

Emerson SH (1938) The genetics of self-incompatibility in $O e$ nothera organensis. Genetics 23:190-202

Ewens WJ (1964) The distribution of self-sterility alleles. Genetics 50:1433-1438

Falconer DS (1960) Introduction to quantitative genetics. Oliver \& Boyd, Edinburgh

Ganders F (1979) Evolution of heterostyly. NZ J Bot $17: 607-635$

Givnish T (1982) Outcrossing versus ecological constraints in the evolution of dioecy. Am Nat 119:849-865

Gottlieb LD (1982) Conservation and duplication of isozymes in plants. Science 216:373-380

Gould SJ, Vrba E (1982) Exaptation - a missing term in the science of form. Paleobiology 8:4-15

Grant V (1975) Genetics of flowering plants. Columbia University Press, New York

Heslop-Harrison J (1983) Self-incompatibility: phenomenology and physiology. Proc R Soc London Ser B 218:371-395

Holsinger K (1986) Dispersal and plant mating systems: the evolution of self-fertilization in subdivided populations. Evolution 40:405-413

Jagorski JS, Ascher PD, Widmer RE (1983) Multigenic selfincompatibility in hexaploid Chrysanthemum. Euphytica $32: 1-7$

Kress WJ (1983) Self-incompatibility in Central America Heliconia. Evolution 37:735-744

Lande R, Schemske D (1985) The evolution of self-fertilization and inbreeding depression in plants. I. Genetic models. Evolution 39:24 40

Larsen K (1977) Self-incompatibility in Beta vulgaris L. I. Four gametophytic, complementary $S$-loci in sugar beet. Hereditas $85: 227-248$

Larsen K (1985) Cell surface recognition glycoproteins and their possible role in angiosperm self-incompatibility. In: Willemse MTM, Went JL van (eds) Sexual reproduction in seed plants, ferns and mosses. Pudoc, Wageningen, pp 112-114

Lawrence MJ, Marshall DF, Curtis VE, Fearon CH (1985) Gametophytic self-incompatibility re-examined: a reply. Heredity 54:131-138

Levin D (1981) Dispersal vs gene flow in plants. Ann Mo Bot Gard 68:233-253

Levin D, Wilson J (1978) The genetic implications of ecological adaptations in plants. In: Freysen A, Woldendorp $J$ (eds) Structure and functioning of plant populations. North Holland, Amsterdam New York, pp 75-100

Lewis D (1979) Genetic versatility of incompatibility in plants NZ J Bot 17:637-644

Lewis D, Rao A (1971) Evolution of dimorphism and population polymorphism in Pemphis acidula Forst. Proc R Soc London Ser B 178:79-94

Lloyd D (1979) Some reproductive factors affecting the selection of self-fertilization in plants. Am Nat 113:67-79

Loveless M, Hamrick J (1984) Ecological determinants of genetic structure in populations. Annu Rev Ecol Syst 14:65-95

Lundqvist A (1962) The nature of the two-loci incompatibility system in grasses. I. The hypothesis of duplicative origin. Hereditas 48:169-181

Lundqvist A (1975) Complex self-incompatibility systems in angiosperms. Proc R Soc London Ser B 188:235-245

Mather K (1973) Genetical structure of populations. Chapman and Hall, London

Maynard Smith J (1978) The evolution of sex. Cambridge University Press, Cambridge

Mayr E (1963) Animal species and evolution. Harvard University Press, Cambridge

McLeod MJ, Guttman SI, Eshbaugh WH, Rayle RE (1983) An electrophoretic study of evolution in Capsicum (Solanaceae). Evolution 37:562-574

Mulcahy DL (1964) The reproductive biology of Oxalis priceae. Am J Bot 51:1045-1050

Mulcahy DL, Mulcahy GB (1983) Gametophytic self-incompatibility re-examined. Science 220:1247-1251

Muenchow G (1981) An S-locus model for the distyly supergene. Am Nat 118:756-760

Muller HJ (1950) Our load of mutations. Am J Hum Genet 2:111-176

Nagylaki T (1975) The deterministic behavior of self-incompatibility alleles. Genetics 79:545-550

Nasrallah J, Kao T, Goldberg M, Nasrallah M (1985) A cDNA clone incoding an S-locus-specific glycoprotein from Brassica oleracea. Nature 318:263-267

Nettancourt D de (1977) Incompatibility in angiosperms. Springer, Berlin Heidelberg New York

Olmstead RG (1986) Self-incompatibility in light of population structure and inbreeding. In: Mulcahy DL, Mulcahy GB, Ottaviano E (eds) Biotechnology and ecology of pollen. Springer, Berlin Heidelberg New York, pp 239-244

Opler AT, Baker H, Frankie G (1980) Plant reproductive characteristics during secondary succession in neotropical lowland forest ecosystems. Biotropica 12 [Suppl]:40-46

Parkin DT (1979) An introduction to evolutionary genetics. Arnold, London 
Partridge L (1983) Non-random mating and offspring fitness. In: Bateson P (ed) Mate choice. Cambridge University Press, Cambridge, pp 227-253

Regal RJ (1977) Ecology and evolution of flowering plant dominance. Science 196:622-629

Richards AJ (1986) Plant breeding systems. Allen and Unwin, London

Ruiz Z, Arroyo T, Arroyo MTK (1978) Plant reproductive ecology of a secondary deciduous tropical forest in Venezuela. Biotropica 10:221-230

Schemske D, Lande R (1985) The evolution of self-fertilization and inbreeding depression in plants. II. Empirical observations. Evolution 39:41-52

Shields WM (1982) Philopatry, inbreeding, and the evolution of sex. State University New York Press, Albany

Shields WM (1983) Optimal inbreeding and the evolution of philopatry. In: Swingland JR, Greenwood PJ (eds) The ecology of animal movement. Clarendon Press, Oxford, pp 132-159

Sobrevila C, Arroyo MTK (1982) Breeding systems in a montane tropical cloud forest in Venezuela. Plant Syst Evol $140: 19-37$

Stebbins GL (1957) Self-fertilization and population variability in the higher plants. Am Nat 91:337-354

Stebbins GL (1974) Flowering plants: evolution above the species level. Harvard University Press, Cambridge

Thompson J, Barrett S (1981) Selection for outcrossing, sexual selection, and the evolution of dioecy in plants. Am Nat $118: 443-449$

Uyenoyama M (1988a) On the evolution of genetic incompatibility systems : incompatibility as a mechanisms for the regulation of outcrossing distance. In: Levin BR, Michod RE (eds) The evolution of sex: an examination of current ideas. Sinauer, Sunderland, Mass, pp 212-232

Uyenoyama M (1988a) On the evolution of genetic incompatibility systems. II. Initial increase of strong gametophytic self-incompatibility under partial selfing and half-sib mating. Am Nat 131:700-722

Weller S (1976) The genetic control of tristyly in Oxalis section Ionoxalis. Heredity 37:387-392

Wiens D (1984) Ovule survivorship, brood size, life history, breeding systems, and reproductive success in plants. Oecologia $64: 47-53$

Whitehouse HKL (1950) Multiple-allelemorph incompatibility of pollen and style in the evolution of angiosperms. Ann Bot (London) 14:198-216

Willson MF (1983) Plant reproductive ecology. Wiley, New York

Wright S (1922) Coefficients of inbreeding and relationship. Am Nat 56:330-338

Wright S (1939) The distribution of self-sterility alleles in populations. Genetics $24: 538-552$

Wright $S$ (1940) Breeding structure of populations in relation to speciation. Am Nat 74:232-248 